\title{
Gastrointestinal symptoms and disorders in patients with eating disorders
}

\author{
Yasuhiro Sato $^{1} \cdot$ Shin Fukudo ${ }^{1,2}$
}

Received: 13 August 2015/Accepted: 7 October 2015/Published online: 26 October 2015

(C) Japanese Society of Gastroenterology 2015

\begin{abstract}
The two most clinically serious eating disorders are anorexia nervosa and bulimia nervosa. A drive for thinness and fear of fatness lead patients with anorexia nervosa either to restrict their food intake or binge-eat then purge (through self-induced vomiting and/or laxative abuse) to reduce their body weight to much less than the normal range. A drive for thinness leads patients with bulimia nervosa to binge-eat then purge but fail to reduce their body weight. Patients with eating disorders present with various gastrointestinal disturbances such as postprandial fullness, abdominal distention, abdominal pain, gastric distension, and early satiety, with altered esophageal motility sometimes seen in patients with anorexia nervosa. Other common conditions noted in patients with eating disorders are postprandial distress syndrome, superior mesenteric artery syndrome, irritable bowel syndrome, and functional constipation. Binge eating may cause acute gastric dilatation and gastric perforation, while self-induced vomiting can lead to dental caries, salivary gland enlargement, gastroesophageal reflux disease, and electrolyte imbalance. Laxative abuse can cause dehydration and electrolyte imbalance. Vomiting and/or laxative abuse can cause hypokalemia, which carries a risk of fatal arrhythmia. Careful assessment and intensive treatment of patients with eating disorders is needed because gastrointestinal symptoms/disorders can progress to a critical condition.
\end{abstract}

Yasuhiro Sato

yassat@hosp.tohoku.ac.jp

1 Department of Psychosomatic Medicine, Tohoku University Hospital, Sendai, Japan

2 Department of Behavioral Medicine, Tohoku University Graduate School of Medicine, Sendai, Japan
Keywords Eating disorder - Anorexia nervosa $\cdot$ Bulimia nervosa $\cdot$ Gastrointestinal symptom · Gastrointestinal disorder

\section{Eating Disorders and Gastrointestinal (GI) Symptoms/Disorders}

The Diagnostic Statistical Manual of Mental Disorders $5^{\text {th }}$ Edition lists several disorders related to eating behaviors [1]. The two most clinically serious eating disorders are anorexia nervosa (AN) and bulimia nervosa (BN). Among patients with $\mathrm{AN}$, a drive for thinness and intense fear of fatness leads them to engage in two types of energy-restricting activities-restricting food intake, which is referred to as $\mathrm{AN}$ of the restrictive type (ANR), and binge eating followed by purging behavior, i.e., self-induced vomiting and/or laxative abuse, which is referred to as AN of the binge-purge type (ANBP). In addition, AN patients perform excessive physical exercise. Together, these activities result in bodyweight loss. Despite the loss of weight, however, AN patients still consider themselves fat (due to body image distortion) and refuse to acknowledge their illness. AN commonly develops in young women, with a prevalence rate in this population of $0.3 \%$ [2]. The mortality rate of AN is $5.1 \%$ per decade [3], which is the highest among mortality rates for stress-related disorders. AN patients frequently present with associated psychiatric disorders such as depression, obsessive-compulsive disorder, and personality disorder [4]. They also show several types of cognitive dysfunction, including cognitive inflexibility [5-7], impaired decision making [8, 9], rewardprocessing disturbance, and altered interoceptive awareness [10]. In many cases, AN patients are resistant to treatment. 
BN patients are also preoccupied with a drive for thinness and engage in binge eating, purging, and exercise. However, they cannot achieve a reduction in body weight and remain at normal weight. As with $\mathrm{AN}, \mathrm{BN}$ tends to develop in adolescence and is prevalent in young women. The prevalence rates for $\mathrm{BN}$ are $1 \%$ in young women and $0.1 \%$ in young men [2]. BN patients also show psychiatric disorders and cognitive dysfunctions. A shift from AN to $\mathrm{BN}$ or from $\mathrm{BN}$ to $\mathrm{AN}$ has been reported in some cases.

Complaints of GI symptoms are frequent among patient with eating disorders. In a study by Salvioli et al. of patients with eating disorders ( 39 with $\mathrm{AN}$ and 9 with $\mathrm{BN}$ ), $96 \%$ reported postprandial fullness, $90 \%$ reported abdominal distention, and more than half complained of abdominal pain, gastric distension, early satiety, and nausea [11]. In addition, Salvioli et al. found a significant correlation between GI symptoms and hypochondriasis. In other studies, AN patients tended to complain of early satiety, post-prandial discomfort or recurrent vomiting [12], severe constipation, and bowel obstruction [13], while BN patients tended to experience bloating $(74.4 \%)$ and flatulence $(74.4 \%)$, followed by constipation $(62.8 \%)$, decreased appetite $(51.2 \%)$, abdominal pain $(48.8 \%)$, borborygmi $(48.8 \%)$, and nausea $(46.5 \%)$ [14].

\section{Common GI Symptoms/Disorders in Patients with Eating Disorders}

\section{Esophageal symptoms and disorders}

Although patients with eating disorders may report disturbances in swallowing, there is little evidence of esophagus malfunction in AN [15]. Such esophageal symptoms without evidence of structural abnormalities, referred to as functional GI disorders (FGID) of the esophagus, include functional dysphagia, globus, and functional heartburn, as defined by the Rome III criteria [16] and co-occur with eating disorders at rates of 6, 1, and $22 \%$, respectively (Fig. 1) [17].

To date, only a few studies have focused on esophageal motor function in patients with eating disorders, despite the clinical importance of evaluating such motor activity. Stacher et al. found that 7 of 30 patients initially diagnosed with AN had esophageal achalasia; one patient had diffuse esophageal spasm, another had severe gastroesophageal reflux disease with upper esophageal sphincter hypertonicity, and 6 had nonpropulsive, repetitive, high-amplitude, prolonged contractions of the lower segment of the esophagus [18]. However, the very high prevalence of esophageal motility disorders among the patients in that study suggests referral bias [15]. Another study showed that the basal pressure of the lower esophageal sphincter was higher in ANR patients than in ANBP patients and

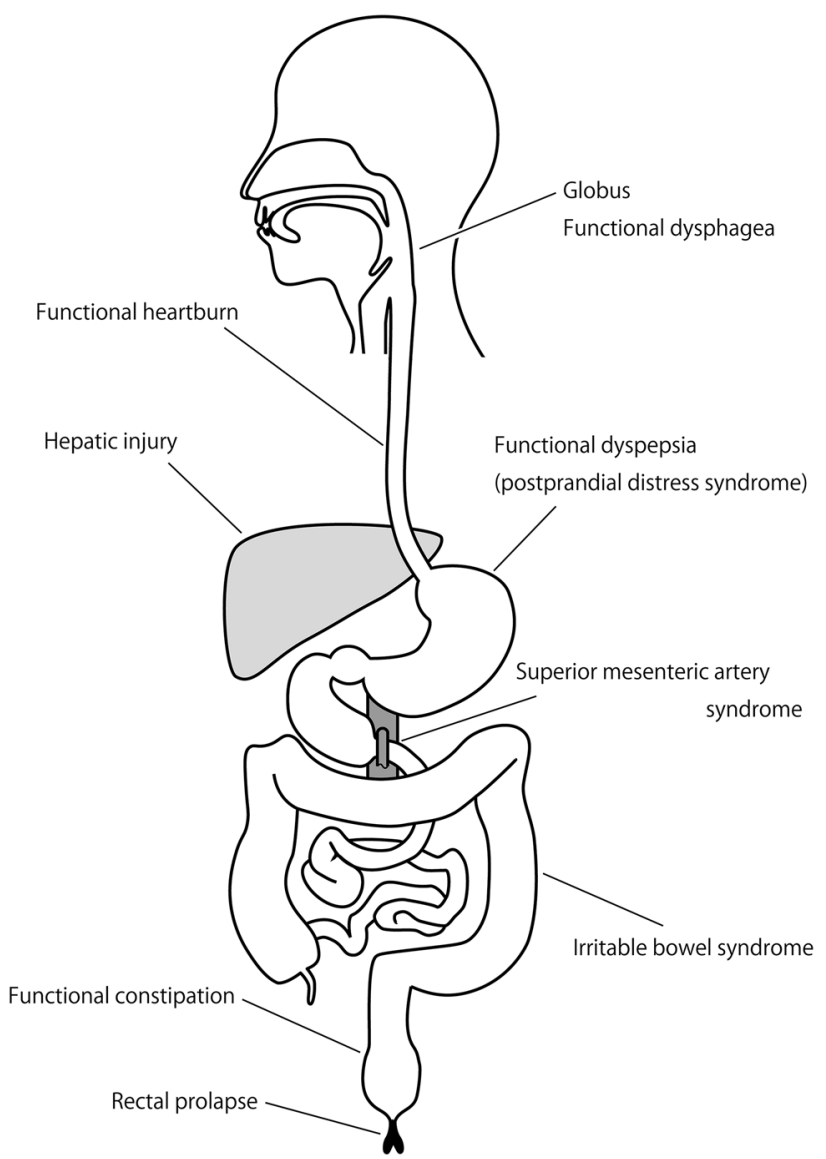

Fig. 1 Gastrointestinal disorders of patients with eating disorders

healthy controls, but still within the normal range [19] and this difference disappeared after treatment. Another study evaluating esophageal motility in $26 \mathrm{BN}$ patients [20] found normal motility in 18 patients, incomplete lower esophageal sphincter relaxation in 4 , vigorous achalasia in 2 , and achalasia and diffuse esophageal spasm in one patient each. In contrast, another study on patients with bulimic eating disorders ( 8 with $\mathrm{BN}$ and 4 with mixed features of $\mathrm{AN}$ and $\mathrm{BN}$ ) revealed normal esophageal motility in all 12 patients [21].

\section{Slow gastric motility and functional dyspepsia}

As mentioned earlier, patients with eating disorders frequently report postprandial fullness, abdominal distention, gastric distension, early satiety, and nausea [11]. Both AN and $\mathrm{BN}$ patients have reported more severe postprandial distress than healthy controls [22]. These symptoms may be attributed to postprandial distress syndrome, a subtype of functional dyspepsia. Functional dyspepsia, itself a type of FGID, manifests as postprandial fullness, early satiation, epigastric pain, or epigastric burning without any structural disease [16]. In patients with eating disorders, one study 
reported a prevalence rate of $45 \%$ for postprandial distress syndrome [17], and another study reported a prevelance rate of $23 \%$ for functional dyspepsia (Fig. 1) [23].

Slow gastric motility contributes to these gastric symptoms. AN patients have shown slow gastric emptying [12, 24-28] in addition to gastric dysrhythmia, impaired antral contractility, delayed emptying of solids, decreased postcibal blood levels of norepinephrine and neurotensin, and impaired autonomic function [26]. Slow gastric emptying in these patients was found to correlate with nausea, vomiting, and gastric fullness [27], and has the potential to lead to difficulties during re-feeding and weight restoration [29].

In BN patients, gastric relaxation after food intake was significantly diminished [30], although gastric emptying was normal $[28,31]$. Gastric compliance in $\mathrm{BN}$ showed no difference from that in controls [32].

Several prokinetic agents have been tested for their effects on delayed gastric emptying. Domperidone, a dopamine D2-receptor selective antagonist used as a prokinetic agent for the stomach, improved delayed gastric emptying in AN patients [18, 33]. Domperidone is available in Japan, but not in the United States. Another prokinetic agent, cisapride, a serotonin 5-HT4 agonist with weak 5-HT3 antagonistic action, effectively enhanced gastric emptying in AN patients [34-36]. However, cisapride is not available in most countries because of the critical cardiac adverse effects of QT prolongation and ventricular tachycardia. Metoclopramide is another dopamine antagonist that proved useful for improving gastric motility [25, 37]. In contrast, the prokinetic agent erythromycin, which is popularly used as an antibiotic, was tested in $\mathrm{BN}$ patients but failed to achieve a significant clinical response [31]. Other prokinetics such as mosapride, itopride, and acotiamide are used in Japan, but these drugs have not been specifically tested in patients with eating disorders.

\section{Superior mesenteric artery syndrome}

Superior mesenteric artery (SMA) syndrome is the result of compression of the third portion of the duodenum, which lies between the aorta and the vertebral column posteriorly and the superior mesenteric artery anteriorly (Fig. 1) [38]. In healthy individuals, the arch of the SMA is held away from the aorta by the mesenteric pad of fat. Considerable loss of mesenteric fat in conditions such as burns, prolonged bedrest, rapid growth in children without corresponding weight gain, and $\mathrm{AN}$, serves to reduce the aortomesenteric angle [39]. Weight loss is regarded to be a risk factor for SMA syndrome [40]. The symptoms of the syndrome are appetite loss, abdominal pain, postprandial distension, abdominal fullness, nausea, and vomiting [41].

Radiological methods are useful for diagnosing SMA syndrome. Barium swallow radiography demonstrates an extremely dilated stomach and restriction of contrast flow past the third portion of the duodenum [42]. Computed tomography (CT) reveals dilation of the stomach and proximal duodenum in addition to severe narrowing of the third portion of the duodenum (Fig. 1). Contrast-enhanced CT reveals compression of the duodenum between the SMA and aorta [42].

SMA syndrome has frequently been reported in AN patients [39, 42-51]. Elbadaway presented four possible explanations for the relationship between SMA syndrome and AN [39]. First, acute or subacute SMA syndrome may develop as a complication in AN patients. Second, chronic SMA syndrome may simulate AN [52]. Third, chronic SMA syndrome may complicate AN, in which case either syndrome may be diagnosed but probably not both. The fourth possibility is that chronic SMA syndrome precipitates AN.

In a case report, Jordaan et al. pointed out that 'Not diagnosing SMA syndrome in a timely fashion may lead to a delay in treatment, prolonged bowel obstruction, and an increased risk of developing fear and avoidance of food' [45]. In their female patient, although they noted interplay between psychological and physical factors and arrived at a diagnosis of 'eating disorder not otherwise specified', the diagnosis according to DSM-5 criteria would be 'restrictive/avoidant food intake disorder'.

In cases of total intestinal obstruction due to SMA syndrome, decompression with nasogastric tube placement and surgical consultation will probably be necessary [42]. Conservative treatments have been used with some patients, including oral hypercaloric liquid feeding [52], nasojejunal tube feeding [42, 49], and total parenteral nutrition [49], whereas other patients have been treated surgically with duodenojejunostomy [39, 43, 45]. These treatments sometime failed because the patients refused to restore their body weight due to a psychopathological desire for thinness.

BN patients rarely develop SMA syndrome because of their normal body weight. Ikegaya et al. reported a fatal case of $\mathrm{BN}$ in a woman who consumed enormous amounts of solid food, where her distended stomach compressed the SMA and pinched the duodenum, eventually leading to fatal total intestinal obstruction [48].

\section{Irritable bowel syndrome}

Irritable bowel syndrome (IBS) is one of the most frequent FGIDs. IBS patients have abdominal pain or discomfort that is relieved with defecation, altered frequency of bowel movement, and altered stool consistency [16]. Four subtypes of IBS have been defined-with diarrhea (IBS-D), with constipation (IBS-C), mixed (IBS-M), and unsubtyped (IBS-U). Approximately $41-52 \%$ of patients with eating disorders have IBS [17, 23, 53], with $68.8 \%$ of $\mathrm{BN}$ 
patients diagnosed with IBS (Fig. 1) [54]. Although none of these studies reported on the subtypes of IBS, IBS-C is probably predominant given that IBS was weakly predicted by laxative use (not abuse) in one study [17].

\section{Constipation}

Constipation is one of the most common GI symptoms among patients with eating disorders. Functional constipation is an FGID with difficult, infrequent, and incomplete defecation that does not fulfill the criteria for IBS [16], i.e., without abdominal pain or discomfort. On the basis of the Rome II or Rome III criteria, 11-24\% of patients with eating disorder are diagnosed with functional constipation [17, 23, 53]. Constipation has been reported in $67-83 \%$ of AN patients [55, 56] and $62.8 \%$ of BN patients (Fig. 1) [14].

Constipation in AN is thought to be caused by reflex hypofunctioning of the colon due to lack of food intake [57] or by poor nutrition and hypokalemia due to purging [29]. The possibility of constipation being caused by antidepressant medication, particularly tricyclic antidepressants, should also be considered in such patients [29]. Low triiodothyronine (T3) syndrome, which is characterized by a markedly decreased T3 level, normal or subnormal thyroxine (T4) level, and normal basal thyrotropin (TSH) level, is a persistent finding in AN [58]. It is thought to be a beneficial response designed to 'spare calories' [59]. This hypothyroidism-like condition may also cause constipation, in addition to dry skin, hypothermia, bradycardia, hypotension, sluggish tendon reflexes, and pleural or pericardial or peritoneal effusions [60].

An investigation using a radiopaque marker revealed that whole-gut transit time was significantly longer in both $\mathrm{AN}$ and BN patients than in controls [61]. In a study using a radiopaque marker and anorectal manometry, 8 of $12 \mathrm{AN}$ patients $(66.7 \%)$ showed slow colonic transit times, while $5(41.7 \%)$ had significantly lower resting anal canal pressures than healthy controls [56]. Colonic transit time normalized in the 8 patients who completed a 4-week refeeding program. However, anorectal manometry did not normalize in these patients. Therefore, pelvic floor dysfunction might be a characteristic trait of AN patients.

Although increased food intake and weight gain appear to relieve constipation to some extent in AN patients, the specific physiologic factors that bring about the improvement in constipation have yet to be determined [62].

\section{Rectal prolapse}

Several case reports have documented the complication of rectal prolapse in patients with eating disorders (Fig. 1) [63-67]. Predisposing risk factors for rectal prolapse include history of pelvic surgery, obstetric trauma, elevated intra-abdominal pressure, advanced age, and chronic constipation [68]. Approximately $80-90 \%$ of patients with rectal prolapse are women [69]. Patients with rectal prolapse exhibit a diminished anal canal pressure [70]. Therefore, patients with eating disorders are predisposed to rectal prolapse.

\section{Hepatic injury}

Many AN patients show liver dysfunction (Fig. 1). Although the liver dysfunction is mild and restores to normalcy with nutritional recovery, some patients can progress to severe hepatic failure that may eventually be fatal [71-73]. Excess accumulation of fat in the liver causes elevation of liver enzymes in AN patients [74]. One report suggests that oxidative stresses in hepatocytes could be related to the pathogenesis of liver injury in AN patients [75].

\section{GI Symptoms Specific to Binge-Purge Behavior}

Both ANBP patients and BN patients consume large amounts of food and then discharge the food with selfinduced vomiting and/or laxative/diuretic abuse. These behaviors can result in serious health problems.

\section{Binge eating}

In the United States, 2.0-3.8 \% of female college students have been reported to be bulimic [76]. In a study of 456 female nursing school and junior college students in Japan, 35 students $(7.7 \%)$ admitted to binge eating more than once a week, $38(8.3 \%)$ to self-induced vomiting, and 21 $(4.5 \%)$ to using laxatives. The reported prevalence of binge-eating behavior among women varies widely depending on the sample population, ranging from $24 \%$ among adults from family practice clinics to $90 \%$ among college students [77].

Several case reports have been published on patients who developed acute gastric dilatation due to excessive food consumption (Fig. 2) [78-80]. Acute gastric dilatation may sometimes be life-threatening, as food compaction in the stomach may obstruct gastric blood circulation, leading to necrosis and perforation of the stomach wall (Fig. 2) [81-84].

\section{Self-induced vomiting}

Many ANBP and BN patients vomit voluntarily after binge eating. In fact, $8.06 \%$ of ANBP patients and $29.50 \%$ of BN patients show Russell's sign - the presence of lesions such as calluses on the dorsal aspect of the hand as a consequence of self-induced vomiting [85]. As the illness 


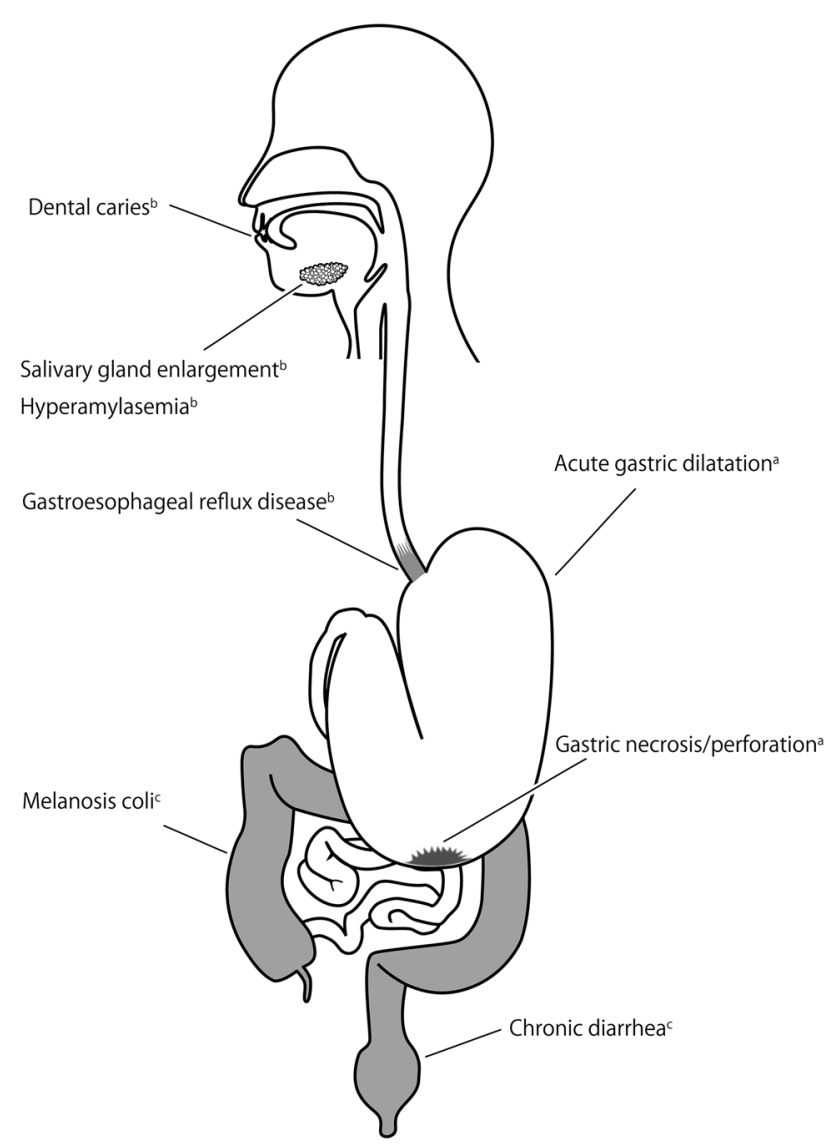

Fig. 2 Gastrointestinal-related binge-purge behavior by patients with eating disorders. a Disorders induced by binge eating, $\mathbf{b}$ disorders induced by self-induced vomiting, $\mathbf{c}$ disorders induced by laxative abuse

progresses, many patients can vomit reflexively without mechanical stimulation [86]. Patients with bulimic behavior present with dysphagia and odynophagia, although their esophageal motility is within normal range [21]. This may be due to continuous acid exposure. Vomited acidic gastric juice causes a number of problems such as dental caries, salivary gland enlargement and inflammation, and gastroesophageal reflux disease (GERD) (Fig. 2).

Mallory-Weiss syndrome is a mucosal and submucosal tear of the esophagus or stomach at or near the gastroesophageal junction [87], and is typically indicated by nonbloody vomiting followed by hematemesis. Although ANBP and BN patients are considered susceptible to this syndrome because they frequently vomit, there is no clear data on the prevalence of the syndrome in eating disorder patients in the English-language literature. Similarly, the prevalence of another severe esophageal complication, esophageal rupture (Boerhaave syndrome), is also unknown.

Kiss et al. performed esophagogastroduodenoscopy in 37 patients with long-standing BN and found the endoscopic appearance of the esophageal and gastric mucosa was normal in 23 patients [88]. However, 8 patients showed signs of mild esophagitis, which were not related to the duration or severity of bulimic behavior or to symptoms of gastroesophageal reflux. Two of these 8 patients had sliding hiatal hernias. The remaining 6 patients had superficial mucosal erythema in the stomach or duodenum but did not exhibit actual erosions, ulcers, or bleeding. Kiss et al. concluded that mucosal injury consequent to chronic, self-induced vomiting in patients with $\mathrm{BN}$ is relatively infrequent and limited. There is no similar report of endoscopy findings in AN patients.

Esophageal achalasia is a dysmotility disorder of unknown etiology, manifesting as dysphagia and vomiting. In this condition, the vomitus is not acidic because the swallowed food stops just above the esophagocardiac junction. Achalasia has been mistaken for eating disorders, particularly in young female AN patients [89-95].

\section{Electrolyte imbalance}

Bulimic patients frequently present with electrolyte abnormalities, with hypokalemia occurring in $0-23.5 \%$ of patients, hypochloremia in 8.8-26.2\%, and elevated bicarbonate levels in 8.2-23.5\% [96]. Hypokalemia is the most serious of these abnormalities since it can cause cardiac arrhythmias, rhabdomyolysis, muscle weakness, hypokalemic cardiomyopathy, and tetany [97]. As well as direct loss of potassium from vomiting, the concomitant loss of chloride ions and gastric acid leads to hypokalemic hypochloremic metabolic alkalosis [97]. The treatment of marked hypokalemic metabolic alkalosis requires volume repletion (with intravenous normal saline) [86], and oral potassium chloride is generally preferred for potassium repletion [86].

\section{Oral symptoms}

Oral lesions such as dental erosion, parotid gland swelling, dental caries, and periodontal disease are frequently noted in eating disorder patients with binge-purge behavior (Fig. 2) [98]. In a university dental clinic, 9 of 400 patients were females with BN [99]. Bulimic patients often report increased sensitivity of the teeth to hot, cold, and acidic substances, suggestive of damage to dental enamel [100]. Gentle brushing and use of a fluoride mouth rinse immediately after purging may prevent caries [86]. Parotid gland swelling is effectively treated with oral administration of pilocarpine hydrochloride [101].

\section{Hyperamylasemia}

In one study, hyperamylasemia was found in $61 \%$ of BN patients and in $20 \%$ of ANR patients (Fig. 2), with more than three-quarters of BN patients showing a close positive 
correlation between the frequency of vomiting and total serum amylase levels, and both frequency and type of vomiting appearing to be associated with the extent of salivary gland enlargement [102]. The hyperamylasemia in patients with $\mathrm{AN}$ or $\mathrm{BN}$ is often caused by increased salivary-type amylase activity [103]. In a study on the amylase and isoamylase activity in 17 patients with eating disorders, 6 showed elevated amylase activity, with 5 of the 6 having isolated increases in salivary isoamylase activity [103]. Hyperamylasemia does not require any treatment.

\section{Gastroesophageal reflux disease}

GERD is a condition characterized by the reverse flow of gastric contents through the esophagus and, in some cases, into the pharynx [100]. In bulimic patients, spontaneous reflux of acidic gastric contents into the lower esophagus may occur due to laxity of the lower esophageal sphincter after repeated vomiting [86]. Endoscopic investigations revealed that 8 of 37 patients with bulimic behavior had mild esophagitis (Fig. 2) [88]. Acid reflux has been observed in $\mathrm{BN}$ patients evaluated by $24-\mathrm{h} \mathrm{pH}$ monitoring and esophagography [104]. Proton-pump inhibitors are the first-line therapy for GERD because of their efficacy, safety, and cost-effectiveness [86].

\section{Esophageal cancer}

Long-term exposure to acidic gastric juice causes Barrett's esophagus, characterized by metaplasia from squamous to columnar epithelium. Barrett's esophagus is a precursor to esophageal adenocarcinoma and increases carcinogenic risk by 11-fold [105]. There have been several case reports of patients with purging behavior who developed Barrett's esophagus [106], which then progressed to esophageal cancer [107, 108]. Other reports have described BN patients who developed esophageal cancer in the absence of Barrett esophagus [109, 110]. In a large cohort study of 3,617 patients with a history of hospitalization for eating disorder, 7 were found to have esophageal cancer [111]. The standardized incidence ratio of patients with eating disorders to the general population was 6.1 in that study. Thus, patients hospitalized previously with eating disorders are thought to be at increased risk of developing esophageal cancer. All the patients with esophageal cancer in the abovementioned study had squamous cell carcinomas although adenocarcinoma would be more in line with expectations. Therefore, the involvement of confounding factors, including alcohol, smoking, and nutritional deficiency, appears to be a more plausible explanation than acidic damage. Further extensive research is needed to elucidate the relationship between self-induced vomiting, Barrett esophagus, and esophageal cancer.

\section{Laxative abuse}

Laxative abuse is another common purging behavior in patients with eating disorders. One study indicated that $36.5 \%$ and $7.9 \%$ of patients with eating disorders reported laxative abuse and enema abuse, respectively [112]. Patients believe that laxatives help to remove the calories in food and keep them thin. However, in fact, only $10-12 \%$ of ingested calories are lost as a result of laxative use because laxatives have little effect on the small intestine where caloric absorption primarily occurs [86].

Chronic watery diarrhea (Fig. 2) caused by laxative abuse leads to dehydration and electrolyte imbalance. Laxative abuse results in the loss of potassium and bicarbonate via the stool, resulting in hypokalemia and nonanion gap metabolic acidosis [97]. The development of hypokalemia may be marked by generalized muscle weakness, lassitude, skeletal muscle paralysis, rhabdomyolysis with renal impairment, and nerve palsies [113]. More severe hypokalemia can result in cardiac arrhythmias, with an increased risk of sudden death. Expulsion of water via stool causes dehydration, leading to hypotension, tachycardia, postural dizziness, and syncope [113].

Melanosis coli, or pseudomelanosis coli, refers to darkening of the colonic mucosa as a result of chronic use of laxatives, especially anthraquinone derivatives (Fig. 2) [114]. No correlation between colorectal cancer and melanosis coli or laxative use has been noted [115]. The condition can resolve gradually after laxative withdrawal [114].

So-called 'cathartic colon' is a loss of normal colonic peristalsis because of long-term habituation to stimulant laxatives. However, the cathartic colon is not induced by currently available laxatives even when used over long periods or in excessive doses [116]. Cathartic colon must not be mistaken for laxative abuse.

Patients' erroneous beliefs about the normal number and frequency of bowel movements are usually obstacles in the treatment of laxative abuse, so educating them on normal bowel physiology is an essential first step in treatment [113]. Patients with eating disorders have been reported to have increased anxiety levels with laxative withdrawal [117]. Body weight gain due to constipation and edema due to fluid retention may contribute to their increasing anxiety, and close supervision is required during this time to ensure that withdrawal is successful [113].

\section{Conclusion}

Patients with eating disorders present with various GI symptoms/disorders, some of which are critical. Therefore, careful assessment and intensive treatment is needed. Data on the prevalence of GI symptoms/disorders in patients 
with eating disorders have been mainly obtained from small-scale studies. As such, comprehensive and extensive surveys on GI symptoms/disorders are necessary among patients with eating disorders to elucidate the actual nature of these intractable disorders and facilitate the development of innovative treatment strategies. Few clinical trials have been conducted on therapeutic measures for GI symptoms/ disorders in patients with eating disorder patients, and to achieve better treatment outcomes, large randomized control trials are warranted.

\section{Compliance with ethical standards}

Conflict of Interest: Yasuhiro Sato and Shin Fukudo declare that they have no conflict of interest.

\section{References}

1. Psychiatric Association, A.P.A.D.-T.F., Diagnostic and statistical manual of mental disorders : DSM-5. 2013, Washington, DC: American Psychiatric Pub

2. Hoek HW, van Hoeken D. Review of the prevalence and incidence of eating disorders. Int J Eat Disord. 2003;34(4):383-96.

3. Arcelus J, Mitchell AJ, Wales J, Nielsen S. Mortality rates in patients with anorexia nervosa and other eating disorders. A meta-analysis of 36 studies. Arch Gen Psychiatry. 2011;68(7):724-31.

4. O'Brien KM, Vincent NK. Psychiatric comorbidity in anorexia and bulimia nervosa: nature, prevalence, and causal relationships. Clin Psychol Rev. 2003;23:57-74.

5. Fassino S, Pieró A, Daga GA, Leombruni P, Mortara P, Rovera GG. Attentional biases and frontal functioning in anorexia nervosa. Int J Eat Disord. 2002;31(3):274-83.

6. Tchanturia K, Davies H, Roberts M, et al. Poor cognitive flexibility in eating disorders: examining the evidence using the Wisconsin Card Sorting Task. PLoS ONE. 2012;7(1):e28331.

7. Sato Y, Saito N, Utsumi A, et al. Neural basis of impaired cognitive flexibility in patients with anorexia nervosa. PLoS ONE. 2013;8(5):e61108.

8. Cavedini P, Bassi T, Ubbiali A, et al. Neuropsychological investigation of decision-making in anorexia nervosa. Psychiatry Res. 2004;127(3):259-66.

9. Tchanturia K, Liao PC, Uher R, et al. An investigation of decision making in anorexia nervosa using the Iowa Gambling Task and skin conductance measurements. J Int Neuropsychol Soc. 2007;13(4):635-41.

10. Kaye WH, Wierenga CE, Knatz S, et al. Temperament-based treatment for anorexia nervosa. Eur Eat Disord Rev. 2015;23(1):12-8.

11. Salvioli B, Pellicciari A, Iero L, et al. Audit of digestive complaints and psychopathological traits in patients with eating disorders: a prospective study. Dig Liver Dis. 2013;45(8):639-44.

12. Holt S, Ford MJ, Grant S, Heading RC. Abnormal gastric emptying in primary anorexia nervosa. $\mathrm{Br} \mathrm{J}$ Psychiatry. 1981;139:550-2.

13. Beumont PJ, Russell JD, Touyz SW. Treatment of anorexia nervosa. Lancet. 1993;341(8861):1635-40.

14. Chami TN, Andersen AE, Crowell MD, et al. Gastrointestinal symptoms in bulimia nervosa: effects of treatment. Am J Gastroenterol. 1995;90(1):88-92.
15. Chial HJ, McAlpine DE, Camilleri M. Anorexia nervosa: manifestations and management for the gastroenterologist. Am J Gastroenterol. 2002;97(2):255-69.

16. Drossman DA, Corazziari E, Delvaux M, et al. ROME III, the Functional Gastrointestinal Disorders, 3rd edn. McLean: Degnon Associates Inc; 2006.

17. Wang X, Luscombe GM, Boyd C, et al. Functional gastrointestinal disorders in eating disorder patients: altered distribution and predictors using ROME III compared to ROME II criteria. World J Gastroenterol. 2014;20(43):16293-9.

18. Stacher G, Kiss A, Wiesnagrotzki S, et al. Oesophageal and gastric motility disorders in patients categorised as having primary anorexia nervosa. Gut. 1986;27(10):1120-6.

19. Benini L, Todesco T, Frulloni L, et al. Esophageal motility and symptoms in restricting and binge-eating/purging anorexia. Dig Liver Dis. 2010;42(11):767-72.

20. Kiss A, Bergmann H, Abatzi TA, et al. Oesophageal and gastric motor activity in patients with bulimia nervosa. Gut. 1990;31(3):259-65.

21. Nickl NJ, Brazer SR, Rockwell K, Smith JW. Patterns of esophageal motility in patients with stable bulimia. Am J Gastroenterol. 1996;91(12):2544-7.

22. Santonicola A, Siniscalchi M, Capone P, et al. Prevalence of functional dyspepsia and its subgroups in patients with eating disorders. World J Gastroenterol. 2012;18(32):4379-85.

23. Boyd C, Abraham S, Kellow J. Psychological features are important predictors of functional gastrointestinal disorders in patients with eating disorders. Scand $\mathrm{J}$ Gastroenterol. 2005;40(8):929-35.

24. Dubois A, Gross HA, Ebert MH, Castell DO. Altered gastric emptying and secretion in primary anorexia nervosa. Gastroenterology. 1979;77(2):319-23.

25. McCallum RW, Grill BB, Lange R, et al. Definition of a gastric emptying abnormality in patients with anorexia nervosa. Dig Dis Sci. 1985;30(8):713-22.

26. Abell TL, Malagelada JR, Lucas AR, et al. Gastric electromechanical and neurohormonal function in anorexia nervosa. Gastroenterology. 1987;93(5):958-65.

27. Rigaud D, Bedig G, Merrouche M, et al. Delayed gastric emptying in anorexia nervosa is improved by completion of a renutrition program. Dig Dis Sci. 1988;33(8):919-25.

28. Robinson PH, Clarke M Barrett, J. Determinants of delayed gastric emptying in anorexia nervosa and bulimia nervosa. Gut, 1988. 29(4): p. 458-64.

29. Zipfel S, Sammet I, Rapps N, et al. Gastrointestinal disturbances in eating disorders: clinical and neurobiological aspects. Auton Neurosci. 2006;129(1-2):99-106.

30. Walsh BT, Zimmerli E, Devlin MJ, et al. A disturbance of gastric function in bulimia nervosa. Biol Psychiatry. 2003;54(9):929-33.

31. Devlin MJ, Kissileff HR, Zimmerli EJ, et al. Gastric emptying and symptoms of bulimia nervosa: effect of a prokinetic agent. Physiol Behav. 2012;106(2):238-42.

32. Zimmerli EJ, Walsh BT, Guss JL, et al. Gastric compliance in bulimia nervosa. Physiol Behav. 2006;87(2):441-6.

33. Russell DM, Freedman ML, Feiglin DH, et al. Delayed gastric emptying and improvement with domperidone in a patient with anorexia nervosa. Am J Psychiatry. 1983;140(9):1235-6.

34. Stacher G, et al. Gastric emptying, body weight and symptoms in primary anorexia nervosa. Long-term effects of cisapride. $\mathrm{Br} \mathrm{J}$ Psychiatry. 1993;162:398-402.

35. Stacher G, Bergmann H, Wiesnagrotzki S, et al. Intravenous cisapride accelerates delayed gastric emptying and increases antral contraction amplitude in patients with primary anorexia nervosa. Gastroenterology. 1987;92(4):1000-6. 
36. Szmukler GI, Young GP, Miller G, et al. A controlled trial of cisapride in anorexia nervosa. Int $\mathrm{J}$ Eat Disord. 1995; 17(4):347-57.

37. Domstad PA, Shih WJ, Humphries L, et al. Radionuclide gastric emptying studies in patients with anorexia nervosa. J Nucl Med. 1987;28(5):816-9.

38. Adson DE, Mitchell JE, Trenkner SW. The superior mesenteric artery syndrome and acute gastric dilatation in eating disorders: a report of two cases and a review of the literature. Int $\mathbf{J}$ Eat Disord. 1997;21(2):103-14.

39. Elbadaway MH. Chronic superior mesenteric artery syndrome in anorexia nervosa. Br J Psychiatry. 1992;160:552-4.

40. Mathenge N, Osiro S, Rodriguez II. Superior mesenteric artery syndrome and its associated gastrointestinal implications. Clin Anat. 2014;27(8):1244-52.

41. Mansberger AR Jr, Hearn JB, Byers RM, et al. Vascular compression of the duodenum. Emphasis on accurate diagnosis. Am J Surg. 1968;115(1):89-96.

42. Verhoef PA, Rampal A. Unique challenges for appropriate management of a 16-year-old girl with superior mesenteric artery syndrome as a result of anorexia nervosa: a case report. J Med Case Rep. 2009;3:127.

43. Vannatta JB, Cagas CR, Cramer RI. Superior mesenteric artery (Wilkie's) syndrome: report of three cases and review of the literature. South Med J. 1976;69(11):1461-5.

44. Froese AP, Szmuilowicz J, Bailey JD. The superior-mesentericartery syndrome: cause or complication of anorexia nervosa? Can Psychiatr Assoc J. 1978;23(5):325-7.

45. Jordaan GP, Muller A, Greeff M, Stein DJ. Eating disorder and superior mesenteric artery syndrome. J Am Acad Child Adolesc Psychiatry. 2000;39(10):1211.

46. Szajnberg N. Eating disorder and superior mesenteric artery syndrome. J Am Acad Child Adolesc Psychiatry. 2001;40(4):388-9.

47. Lo DY, Yen JL, Jones MP. Massive gastric dilation and necrosis in anorexia nervosa: cause or effect?. Nutr Clin Pract. 2004;19(4):409-12.

48. Ikegaya H, Nakajima M, Shintani-Ishida K, et al. Death due to duodenal obstruction in a patient with an eating disorder: a case report. Int J Eat Disord. 2006;39(4):350-2.

49. Moreno MA, Smith MS. Anorexia in a 14-year-old girl: why won't she eat?. J Adolesc Health. 2006;39(6):936-8.

50. Gwee K, Teh A, Huang C. Acute superior mesenteric artery syndrome and pancreatitis in anorexia nervosa. Australas Psychiatry. 2010;18(6):523-6.

51. Rehman A, et al. Wilkie's syndrome. J Coll Physicians Surg Pak. 2011;21(1):43-5.

52. Kornmehl P, Weizman Z, Liss Z, et al. Superior mesenteric artery syndrome presenting as an anorexia nervosa-like illness. J Adolesc Health Care. 1988;9(4):340-3.

53. Abraham S, Kellow JE. Do the digestive tract symptoms in eating disorder patients represent functional gastrointestinal disorders?. BMC Gastroenterol. 2013;13:38.

54. Dejong H, Perkins S, Grover M, Schmidt U. The prevalence of irritable bowel syndrome in outpatients with bulimia nervosa. Int J Eat Disord. 2011;44(7):661-4.

55. Sileri P, Franceschilli L, De Lorenzo A, et al. Defecatory disorders in anorexia nervosa: a clinical study. Tech Coloproctol. 2014;18(5):439-44.

56. Chiarioni G, Bassotti G, Monsignori A, et al. Anorectal dysfunction in constipated women with anorexia nervosa. Mayo Clin Proc. 2000;75(10):1015-9.

57. Chun AB, Sokol MS, Kaye WH, et al. Colonic and anorectal function in constipated patients with anorexia nervosa. Am J Gastroenterol. 1997;92(10):1879-83.
58. Støving RK, Hangaard J, Hansen-Nord M, Hagen C. A review of endocrine changes in anorexia nervosa. J Psychiatr Res. 1999;33(2):139-52.

59. Fragidis S, Sombolos K, Thodis E, et al. Low T3 syndrome and long-term mortality in chronic hemodialysis patients. World $\mathrm{J}$ Nephrol. 2015;4(3):415-22.

60. Bello G, Ceaichisciuc I, Silva S, Antonelli M. The role of thyroid dysfunction in the critically ill: a review of the literature. Minerva Anestesiol. 2010;76(11):919-28.

61. Kamal N, Chami T, Andersen A, et al. Delayed gastrointestinal transit times in anorexia nervosa and bulimia nervosa. Gastroenterology. 1991;101(5):1320-4.

62. Hadley SJ, Walsh BT. Gastrointestinal disturbances in anorexia nervosa and bulimia nervosa. Curr Drug Targets CNS Neurol Disord. 2003;2(1):1-9.

63. Dreznik Z, Vishne TH, Kristt D, et al. Rectal prolapse: a possibly underrecognized complication of anorexia nervosa amenable to surgical correction. Int $\mathrm{J}$ Psychiatry Med. 2001;31(3):347-52.

64. Guerdjikova AI, O’Melia A, Riffe K, et al. Bulimia nervosa presenting as rectal purging and rectal prolapse: case report and literature review. Int J Eat Disord. 2012;45(3):456-9.

65. Malik M, Stratton J, Sweeney WB. Rectal prolapse associated with bulimia nervosa: report of seven cases. Dis Colon Rectum. 1997;40(11):1382-5.

66. Marceau C, Parc Y, Debroux E, et al. Complete rectal prolapse in young patients: psychiatric disease a risk factor of poor outcome. Colorectal Dis. 2005;7(4):360-5.

67. Mitchell N, Norris ML. Rectal prolapse associated with anorexia nervosa: a case report and review of the literature. $\mathrm{J}$ Eat Disord. 2013;1:39.

68. Peters WA, Smith MR, Drescher CW, Rectal prolapse in women with other defects of pelvic floor support. Am J Obstet Gynecol, 2001. 184(7): p. 1488-94; discussion 1494-5.

69. Gourgiotis S, Baratsis S. Rectal prolapse. Int J Colorectal Dis. 2007;22(3):231-43.

70. Roig JV, Buch E, Alós R, et al. Anorectal function in patients with complete rectal prolapse. Differences between continent and incontinent individuals. Rev Esp Enferm Dig. 1998;90(11):794-805.

71. De Caprio C, Alfano A, Senatore I, et al. Severe acute liver damage in anorexia nervosa: two case reports. Nutrition. 2006;22(5):572-5.

72. Di Pascoli $\mathrm{L}$, et al. Acute liver damage in anorexia nervosa. Int $\mathrm{J}$ Eat Disord. 2004;36(1):114-7.

73. Furuta S, Ozawa Y, Maejima K, et al. Anorexia nervosa with severe liver dysfunction and subsequent critical complications. Intern Med. 1999;38(7):575-9.

74. Sakada M, Tanaka A, Ohta D, et al. Severe steatosis resulted from anorexia nervosa leading to fatal hepatic failure. J Gastroenterol. 2006;41(7):714-5.

75. Tajiri K, Shimizu Y, Tsuneyama K. Sugiyama T.A case report of oxidative stress in a patient with anorexia nervosa. Int J Eat Disord. 2006;39(7):616-8.

76. Thelen MH, Mann LM, Pruitt J, Smith M. Bulimia: prevalence and component factors in college women. J Psychosom Res. 1987;31(1):73-8.

77. Connors ME, Johnson CL. Epidemiology of bulimia and bulimic behaviors. Addict Behav. 1987;12(2):165-79.

78. Russell GF. Acute dilatation of the stomach in a patient with anorexia nervosa. Br J Psychiatry. 1966;112(483):203-7.

79. Jennings KP, Klidjian AM. Acute gastric dilatation in anorexia nervosa. Br Med J. 1974;2(5917):477-8.

80. Brook GK. Acute gastric dilatation in anorexia nervosa. Br Med J. 1977;2(6085):499-500. 
81. Saul SH, Dekker A, Watson CG. Acute gastric dilatation with infarction and perforation. Report of fatal outcome in patient with anorexia nervosa. Gut, 1981. 22(11): p. 978-83.

82. Abdu RA, Garritano D, Culver O. Acute gastric necrosis in anorexia nervosa and bulimia. Two case reports. Arch Surg. 1987;122(7):830-2.

83. Reeve T, et al. Near-total gastric necrosis caused by acute gastric dilatation. South Med J. 1988;81(4):515-7.

84. Patocskai EJ, Thomas JM. Gastric necrosis in a patient with bulimia. Eur J Surg. 2002;168(5):302-4.

85. Glorio R, Allevato M, De Pablo A, et al. Prevalence of cutaneous manifestations in 200 patients with eating disorders. Int $\mathrm{J}$ Dermatol. 2000;39(5):348-53.

86. Mehler PS. Medical complications of bulimia nervosa and their treatments. Int J Eat Disord. 2011;44(2):95-104.

87. Midgley RC, Cantor D. Upper gastrointestinal hemorrhagediagnosis and management. West J Med. 1977;127(5):371-7.

88. Kiss A, Wiesnagrotzki S, Abatzi TA, et al. Upper gastrointestinal endoscopy findings in patients with long-standing bulimia nervosa. Gastrointest Endosc. 1989;35(6):516-8.

89. Stacher G, Wiesnagrotzki S, Kiss A. Symptoms of achalasia in young women mistaken as indicating primary anorexia nervosa. Dysphagia. 1990;5(4):216-9.

90. Duane PD, Magee TM, Alexander MS, et al. Oesophageal achalasia in adolescent women mistaken for anorexia nervosa. BMJ. 1992;305(6844):43.

91. Richterich A, Brunner R. ReschF. Achalasia mimicking prepubertal anorexia nervosa. Int J Eat Disord. 2003;33(3):356-9.

92. Desseilles M, Fuchs S, Ansseau M, et al. Achalasia may mimic anorexia nervosa, compulsive eating disorder, and obesity problems. Psychosomatics. 2006;47(3):270-1.

93. Garcia Júnior C, Araújo OF, Murro AL, et al., Idiopathic achalasia mistakenly diagnosed as anorexia nervosa. Rev Bras Psiquiatr, 2008. 30(2): p. 168.

94. Däbritz J, Domagk D, Monninger M, Foell D. Achalasia mistaken as eating disorders: report of two children and review of the literature. Eur J Gastroenterol Hepatol. 2010;22(7):775-8.

95. Goldsmith PJ, Decadt B. Extreme achalasia presenting as anorexia nervosa. Case Rep Surg. 2012;2012:985454.

96. Crow SJ, Salisbury JJ, Crosby RD, Mitchell JE. Serum electrolytes as markers of vomiting in bulimia nervosa. Int $\mathrm{J}$ Eat Disord. 1997;21(1):95-8.

97. Lasater LM, Mehler PS. Medical complications of bulimia nervosa. Eat Behav. 2001;2(3):279-92.

98. Romanos GE, Javed F, Romanos EB, Williams RC. Oro-facial manifestations in patients with eating disorders. Appetite. 2012;59(2):499-504.

99. Valena V, Young WG. Dental erosion patterns from intrinsic acid regurgitation and vomiting. Aust Dent J. 2002;47(2):106-15.
100. Mendell DA, Logemann JA. Bulimia and swallowing: cause for concern. Int J Eat Disord. 2001;30(3):252-8.

101. Mehler PS, Wallace JA. Sialadenosis in bulimia. A new treatment. Arch Otolaryngol Head Neck Surg. 1993;119(7):787-8.

102. Kinzl J, Biebl W, Herold M. Significance of vomiting for hyperamylasemia and sialadenosis in patients with eating disorders. Int J Eat Disord. 1993;13(1):117-24.

103. Humphries LL, et al. Hyperamylasemia in patients with eating disorders. Ann Intern Med. 1987;106(1):50-2.

104. Rothstein SG. Reflux and vocal disorders in singers with bulimia. J Voice. 1998;12(1):89-90.

105. Chandra S, Gorospe EC, Leggett CL, Wang KK. Barrett's esophagus in 2012: updates in pathogenesis, treatment, and surveillance. Curr Gastroenterol Rep. 2013;15(5):322.

106. Pacciardi B, Cargioli C, Mauri M. Barrett's esophagus in anorexia nervosa: a case report. Int $\mathrm{J}$ Eat Disord. 2015;48(1):147-50.

107. Navab F, Avunduk C, Gang D, Frankel K. Bulimia nervosa complicated by Barrett's esophagus and esophageal cancer. Gastrointest Endosc. 1996;44(4):492-4.

108. Dessureault S, Coppola D, Weitzner M, et al. Barrett's esophagus and squamous cell carcinoma in a patient with psychogenic vomiting. Int J Gastrointest Cancer. 2002;32(1):57-61.

109. Shinohara ET, Swisher-McClure S, Husson M, et al. Esophageal cancer in a young woman with bulimia nervosa: a case report. J Med Case Rep. 2007;1:160.

110. Buyse S, Nahon S, Tuszynski T, Delas N. Bulimia nervosa as a risk factor for squamous cell carcinoma of the esophagus?. Am J Gastroenterol. 2003;98(6):1442-3.

111. Brewster DH, Nowell SL, Clark DN. Risk of oesophageal cancer among patients previously hospitalised with eating disorder. Cancer Epidemiol. 2015;39(3):313-20.

112. Winstead NS, Willard SG. Gastrointestinal complaints in patients with eating disorders. $\mathrm{J}$ Clin Gastroenterol. 2006;40(8):678-82.

113. Roerig JL, Steffen KJ, Mitchell JE, Zunker C. Laxative abuse: epidemiology, diagnosis and management. Drugs. 2010;70(12):1487-503.

114. Li D, Browne LW, Ladabaum U. Melanosis coli. Clin Gastroenterol Hepatol. 2009;7(9):A20.

115. Nusko G, Schneider B, Ernst H, et al. Melanosis coli-a harmless pigmentation or a precancerous condition?. Z Gastroenterol. 1997;35(5):313-8.

116. Müller-Lissner S. What has happened to the cathartic colon? Gut. 1996;39(3):486-8.

117. Weltzin TE, Bulik CM, McConaha CW, Kaye WH. Laxative withdrawal and anxiety in bulimia nervosa. Int $\mathrm{J}$ Eat Disord. 1995;17(2):141-6. 